\title{
Sound Quality Subjective Evaluation Analysis of Noise Inside High-speed Trains
}

\author{
Xiaojuan ZHANG \\ School of Traffic and Transportation Engineering, \\ Dalian Jiaotong University. \\ Dalian, China \\ ly@djtu.edu.cn \\ Xiaojuan ZHANG \\ Department of Mechanical Engineering \\ Dalian Institute of Science and Technology \\ Dalian,China \\ dalianxiaojuan@163.com
}

\author{
Yan LIU \\ School of Traffic and Transportation Engineering, \\ Dalian Jiaotong University. \\ Dalian, China
}

\author{
Changbin ZHANG \\ Academic Service Section \\ Dalian Jiaotong University. \\ Dalian, China \\ zhangpeiguang21@163.com
}

\begin{abstract}
The paper studied paired comparison method, system researching experiments design, process, data analysis, and misjudgment analysis, etc. Paired comparison method has their own advantages; experimental data reliability and accuracy need to be further validation. The paper using Pearson correlation coefficient to verify the data accuracy and correlation coefficient is more than 0.72.At the end, preference value of sound samples is inverse proportion to loudness, as to A written right pressure level shows no relationship. The paper has certain reference for valid evaluating acoustic environmental quality in High-speed Trains.
\end{abstract}

Key words-high-speed railway passenger trains, sound quality, paired comparison method, Subjective evaluation

\section{INTRODUCTION}

Reference [1] analyzed objective parameters of high-speed railway passenger trains about sound quality in different speed. Researching objective parameters provides basis for sound quality applied research on railway passenger trains. Sound quality is a systematic project, so we also cannot ignore the importance and role of subjective evaluation.

Germany's Blauert and Bodden point out the meaning of sound quality: product's sound quality is appropriate description noise attached to product sound, and it is judgment and evaluation of the overall hearing voice characteristics, evaluation process can't do without product itself attributes and characteristics[2]. For product's sound quality analysis is based on sound source, auditory perception and subjective evaluation. Sound source is noise testing objects, its relationship with auditory perception, sensitive degree about ears to acoustical signals and physiological acoustics, the main body's subjective judgment is subjective evaluation. The paper researched paired comparison method taking noise samples in different operation speeds of high-speed trains..Through researching experiments process, proving experiment data correctness and effectiveness using statistics corresponding

Sponsors: National Power Traction Laboratory of Southwest Jiaotong University (Project number: TPL1207) methods, it is a good example for railway passenger train's sound quality experiments developing smoothly.

\section{PAIRED COMPARISON METHOD ABOUT INSIDE HIGH-SPEED TRAINS}

\section{A. Collecting evaluation samples}

The sound samples comes from moving railway trains using German's Head Acousties company HMSIII (HeadMeasureSystem) simulation people's head and SQlabII multi-channel test system. The first position of Simulation people's head is on the seat in ordinary pack, the second position is on the seat of senior pack. The train's speed of collection noise sample as shown in table 1 . We get 14 stability effective samples through collecting samples. Considering the formation process of subjective perception of ear hearing and sample time, so every samples length is $5 \mathrm{~s}[3]$.

TABBEL1 OPERATION CONDITION OF HIGH-SPEED TRAIN

\begin{tabular}{|c|c|c|c|c|c|}
\hline $\begin{array}{c}\text { Serial } \\
\text { number }\end{array}$ & 1 & 2 & 3 & 4 & 5 \\
\hline $\begin{array}{c}\text { Spped } \\
\text { km/h }\end{array}$ & 300 & 315 & 330 & 350 & 360 \\
\hline $\begin{array}{c}\text { Positio } \\
\mathbf{n}\end{array}$ & $\begin{array}{c}\text { Ordina } \\
\text { ry pack }\end{array}$ & $\begin{array}{c}\text { Ordinary } \\
\text { pack }\end{array}$ & $\begin{array}{c}\text { Ordinary } \\
\text { pack }\end{array}$ & $\begin{array}{c}\text { Ordinary } \\
\text { pack }\end{array}$ & $\begin{array}{c}\text { Ordinary } \\
\text { pack }\end{array}$ \\
\hline $\begin{array}{c}\text { Serial } \\
\text { number }\end{array}$ & 6 & 7 & 8 & 9 & 10 \\
\hline $\begin{array}{c}\text { Spped } \\
\text { km/h }\end{array}$ & 385 & 330 & 350 & 360 & 385 \\
\hline $\begin{array}{c}\text { Positio } \\
\mathbf{n}\end{array}$ & $\begin{array}{c}\text { Ordina } \\
\text { ry pack }\end{array}$ & $\begin{array}{c}\text { Senior } \\
\text { pack }\end{array}$ & $\begin{array}{c}\text { Senior } \\
\text { pack }\end{array}$ & $\begin{array}{c}\text { Senior } \\
\text { pack }\end{array}$ & $\begin{array}{c}\text { Senior } \\
\text { pack }\end{array}$ \\
\hline
\end{tabular}

\section{B. Selected evaluator}

According experience of subjective evaluation experi-ment, 20 evaluators are enough [3], so we decided 20 evaluators to take part in paired comparison experiments. Their average age 
is 24 years old, all hearing ability are normal. Among them, there are 16 people studying noise issues. They all understand evaluation process and evaluation about this trial.

\section{C. designing paired comparison method}

Paired comparison method is that all samples will be according to certain arrangement pair, and play pair one and one; evaluator need make judgment about every pair [4]. This experiment choose according preference, each group evaluation samples are divided into A, B sample, if evaluator thinks A quality is better than $B$, making" $\sqrt{ }$ "below A; on the contrary making" $\sqrt{ }$ "below $\mathrm{B}$, if $\mathrm{A}$ is as better as $\mathrm{B}$, making" $\checkmark$ "below A and B. In order to reduce workload, we used half Angle matrix method, that will not impact assessment effectiveness. There are 66 pairs about I-j comparison, aided design 6 pairs same sample I-I comparison and 12 pairs different order playback I-j and j-I comparison; the total of pairs are 84. Each sound sample duration 5s, time interval between two samples about 2 s, each sample evaluation time about 13s, so complete evaluation need about 30 minutes, that accord with foreign quality evaluation [5]. Experimental process is shown in figure 1 .

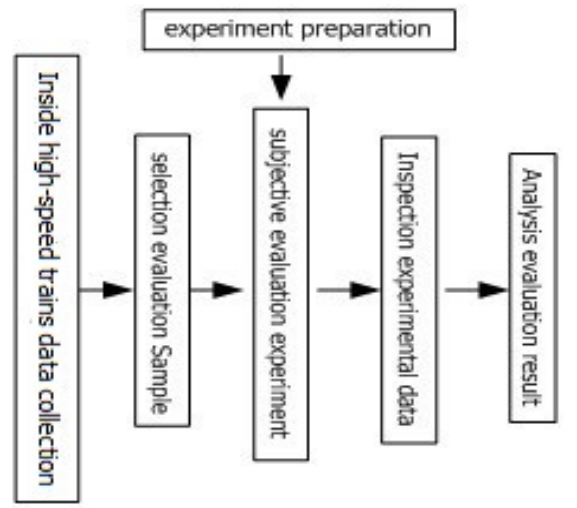

- $\quad$ Figure1 Subjective evaluation experiment flow chart

\section{EXPERIMENT DATA PROCESSING}

In order to statistic experiment data, we need certain score to the choice of each time, such as shown in table 2.

TABBEL2 PAIRED COMPARISON EXPERIMENT ASSIGNMENT DEFINITION

\begin{tabular}{|c|c|}
\hline Assignment condition & Value \\
\hline A better & 1 \\
\hline B better & -1 \\
\hline A and B nearly same & 0 \\
\hline
\end{tabular}

\section{A. Data reliability testing}

Subjective evaluation experiment depend on evaluation of subjective judgment heavily, there are three possible cases during evaluation [6]: (1) evaluator losing concentration, (2) evaluation standards revising constantly, (3) evaluator confused to distinguish and judgment which sample is good. In order to obtain effective experimental data, we have to make corresponding inspection.

In this experiment in the same event A-A easily identification, its error rate is lowest, average rate is $10.8 \%$;
Compared with a different order events is higher, evaluation misjudgment rate is $25.8 \%$, that means transform play order has certain influence to make correct decision; the triangle circulation misjudgment evaluation average rate was $22.2 \%$, through the same sound sample inspection (A-A test), different play order sample inspection (AB-BA test) and triangle circulation misjudgment.

In order to guarantee the reliability of evaluation results, we often need to comprehensive consideration, eliminating misjudgment higher data evaluators to guarantee other data reliability. We used consistency inspection coefficient which is put forward by Kendall to inspection data [7], to eliminate more wrong data, and to ensure subjective evaluation accuracy. Foreign researchers generally think that if consistency coefficient more than 0.6, the experiment data is acceptable, if consistency coefficient better than 0.7, the result is good [8]. According to the right consistency coefficient calculation results, we eventually eliminated lowest right consistency coefficient Tp5, Tp11, Tp20. the other 17 evaluator's t right consistency coefficient are above 0.72 .

In order to further verify 17 evaluators data consistency, we used Pearson's correlation analysis to verdict data consistency [9]. According to evaluation results statistical matrix calculated with SPSS software, we can get 16 subject correlation matrix. The Pearson correlation coefficient among evaluators is between 0.989 and 0.708 , which explain that evaluation data is strong correlation, so the evaluation results are effective.

\section{B.Preference score sort and analysis}

We calculated every samples preference score and average score according to 17 evaluators. Each of average score is corresponding sound samples preference score. According to selected samples operation condition, preference score ascending order is shown in table 3.

TABEL3 SAMPLES SPEED AND PREFERENCE VALUE

\begin{tabular}{|c|c|c|c|c|}
\hline $\begin{array}{c}\text { Sample } \\
\text { number }\end{array}$ & 9 & 4 & 8 & 6 \\
\hline $\begin{array}{c}\text { Operation } \\
\text { condition }\end{array}$ & $\begin{array}{c}G-385 \mathrm{~km} / \mathrm{h} \\
(380 \mathrm{model})\end{array}$ & $\begin{array}{c}245 \mathrm{~km} / \mathrm{h} \\
(250 \mathrm{model}\end{array}$ & $\begin{array}{c}G-360 \mathrm{~km} / \mathrm{h} \\
(380 \mathrm{model})\end{array}$ & $\begin{array}{c}\text { G-330km/h } \\
(380 \mathrm{model})\end{array}$ \\
\hline $\begin{array}{c}\text { Preference } \\
\text { value }\end{array}$ & 0.2 & 1.2 & 2.6 & 2.6 \\
\hline $\begin{array}{c}\text { Sample } \\
\text { number }\end{array}$ & 7 & 5 & 3 & 12 \\
\hline $\begin{array}{c}\text { Operation } \\
\text { condition }\end{array}$ & $\begin{array}{c}G-\mathrm{l} 350 \mathrm{~km} / \mathrm{h} \\
(380 \mathrm{model})\end{array}$ & $\begin{array}{c}G-300 \mathrm{~km} / \mathrm{h} \\
(380 \mathrm{model})\end{array}$ & $\begin{array}{c}215 \mathrm{~km} / \mathrm{h} \\
(250 \mathrm{model})\end{array}$ & $\begin{array}{c}S-385 \mathrm{~km} / \mathrm{h} \\
(380 \mathrm{model})\end{array}$ \\
\hline $\begin{array}{c}\text { Preference } \\
\text { value }\end{array}$ & 2.6 & 3.9 & 5.4 & 5.5 \\
\hline $\begin{array}{c}\text { Sample } \\
\text { number }\end{array}$ & 11 & 10 & 2 & 1 \\
\hline $\begin{array}{c}\text { Operation } \\
\text { condition }\end{array}$ & $\begin{array}{c}360 \mathrm{~km} / \mathrm{h} \\
(380 \mathrm{model})\end{array}$ & $\begin{array}{c}S-350 \mathrm{~km} / \mathrm{h} \\
(380 \mathrm{model})\end{array}$ & $\begin{array}{c}200 \mathrm{~km} / \mathrm{h} \\
(250 \mathrm{model})\end{array}$ & $\begin{array}{c}145 \mathrm{~km} / \mathrm{h} \\
(250 \mathrm{model})\end{array}$ \\
\hline $\begin{array}{c}\text { Preference } \\
\text { value }\end{array}$ & 5.8 & 6.9 & 8.5 & 12.8 \\
\hline
\end{tabular}

Note: G-general, S-Seniors. 
From table3, we can conclude that preference score of samples and running speed of trains are closely linked. 250 railway passenger trains (sample 4, 3, 2, and 1); preference score is lower along with speed increase. The preference score of 380 railway passenger trains senior pack were all higher than general pack, senior pack rooms has good sound absorption and noise reduction measures; preference score is also lower along with speed increase.

\section{RELATIONSHIP BETWEEN PREFERENCE SCORE AND OBJECTIVE PARAMETERS}

Through analysis relationship between subjective evaluation and objective parameters, to obtain subjective evaluation relations relying on objective parameters, so we can seek measures to improve objective parameters to improve subjective perception quantity. The paper discussed relationship between preference score and objective parameters using type 380 railway passenger trains.

TABEL4 EVERY SOUND SAMPLES OBJECTIVE PARAMETER AND PREFRENCE VALUE

\begin{tabular}{|c|c|c|c|c|c|}
\hline Samples & $\begin{array}{c}\text { speed } \\
(\mathbf{k m} / \mathbf{h})\end{array}$ & $\begin{array}{c}\text { Linear } \\
\text { pressure } \\
\text { leveldB }\end{array}$ & $\begin{array}{c}\text { A } \\
\text { pressure } \\
\text { leveldB(A) }\end{array}$ & $\begin{array}{c}\text { soundess } \\
\text { sone }\end{array}$ & prefrence \\
\hline 3 & $G-330$ & 101.6 & 70.1 & 28.4 & 5.4 \\
\hline 5 & $G-300$ & 98.1 & 68.4 & 25.0 & 4.5 \\
\hline 7 & $G-350$ & 100.0 & 68.5 & 25.9 & 3.9 \\
\hline 8 & $G-360$ & 100.5 & 69.7 & 27.7 & 2.6 \\
\hline 9 & $G-385$ & 103.5 & 73.8 & 35.2 & 0.2 \\
\hline 10 & $S-350$ & 101.2 & 64.5 & 19.9 & 6.9 \\
\hline 11 & $S-360$ & 101.9 & 65.0 & 20.3 & 5.8 \\
\hline 12 & $S-385$ & 102.6 & 66.0 & 21.7 & 5.5 \\
\hline
\end{tabular}

In order to data analysis between preference and objective parameters, sample 7's value as benchmark normalization to all samples data in table 4,then all new data to create chart as shown in figure 2.

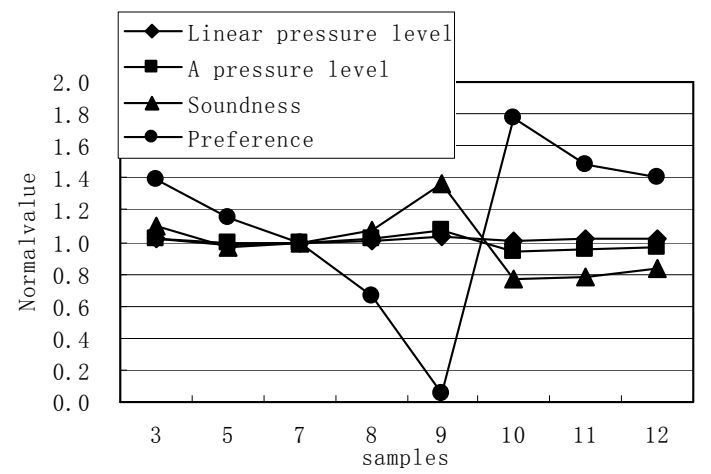

- $\quad$ Figure 2 Relationship graph between preference and objective parameter after normalized
Sample's preference from part Comparison experiments explain that how degree evaluator were fond of each sample. Every objective parameter decrypts size of sound physical quantities.

Through normalized process that can be more clear the relationship between preference and objective parameters. From We can distinctly see that preference and objective parameter are inverse correlation from figure 2, preference and loudness basically is nearly symmetry at the axis of crossroads position, inverse relationship is the strongest; preference and A written right pressure level show weaker inverse relationship; preference and linear pressure level don't present inverse relationship, which explain that the link between them is not close. From figure 2 we can be concluded that the size of sound sample loudness basically decided preference choice of evaluators, a written right pressure level and linear pressure level have little influence to preference choice.

\section{V.CONCLUSION}

Through sound quality subjective evaluation experiments verify that:

- $\quad$ Sound quality subjective evaluation is a kind of effective method to assess railway passenger trains interior sound quality.

- Preference value of sound samples between each evaluator must have strong correlativity relationship.

- $\quad$ Preference value of sound samples about high speed passenger trains interior and objective parameters is an approximate inverse correlation. Loudness is decisive factor for preference value.

\section{REFERENCES}

[1] Y.guixin,noise test and objective parameters analysis of sound quality for high speed trains, CA: noise and vibration control.2011.06, pp.85-88

[2] Rainer Guski,1997,Psychological Methods for Evaluating Sound Qualitu and Assessing Acoustic Information,ACUSTICS/acta acoustica vol.83,pp765-773

[3] M.dongxing, Study on Sound quality Subjective Evaluation and Analysis Methods in interior car[D], CA, Tongji university,shanghai.2003

[4] Hempel T,Chouard N.Evaluation of interior car sound with a new specific semantic differential design[J].J Acoust Soc Am,1999,105(2):pp1280-1285

[5] Norm Otto ans Scott Amman-Ford Motor Company,Chris Eaton-Head acoustics Inc,Scott Lake-General Motors Corporation.Guidelines for Jury Evaluations of Automotive Sounds[J].SAE TECHNICAL PAPER SERIES,1999-01-1822:pp11-12

[6] Weber R.Inteior car sound qualitu-assessment of acceleration noises.2nd Forum Acusticum,Berlin,Germany,1999

[7] Kendall M G.Further Conributions to the Theory of Paired Comparisons[J].Biometrika.1955.11(1):43-62

[8] Parizet E.Pairde Comparison Listening Tests and Circular Error Rates.ACTA Acustica United with Acustica,2002;88(4):pp594-598

[9] ZH wenbo, Practical data statistical analysis and SPSS12.0 applying.Beijing:Posts \& Telecom Press,2006.2 